\title{
Avaliação Pós-Ocupação aplicada em edifícios de escritórios: Alguns aspectos metodológicos e resultados
}

\author{
Sheila Walbe Ornstein \\ Professora titular, Faculdade de Arquitetura e Urbanismo, \\ Núcleo de Pesquisa em Tecnologia da Arquitetura e Urbanismo \\ da Universidade de São Paulo, tel/fax +55 11 3818-3209, \\ e-mail: sheilawo@usp.br
}

Resumo Este artigo pretende demonstrar alguns dos aspectos metodológicos e dos resultados de Avaliação Pós-Ocupação (APO), aplicada em dois edifícios de escritórios, cujas instalações e serviços de apoio apresentam parcialmente características automatizadas e estão situados na região do corredor comercial da avenida Carlos Berrini, no Brooklin Novo, São Paulo.

Abordará e discutirá o formato, o conteúdo e os procedimentos para aplicação de questionário visando aferir a satisfação dos usuários dos dois edifícios e apresentará algumas análises e resultados comparativos no que diz respeito ao ponto de vista dos avaliadores e ao ponto de vista dos usuários, com ênfase nos aspectos funcionais e comportamentais.

Esta discussão é uma contribuição aos procedimentos para aplicação da APO em edifícios de escritórios no Brasil, a qual se iniciou muito recentemente e poderá tomar corpo tendo em vista o crescimento acelerado do setor terciário nas regiões metropolitanas do país. A pesquisa conta com apoio da Fundação de Amparo à Pesquisa do Estado de São Paulo - Fapesp. 
This paper aims to show some of the methodological aspects and the results of a Post-Occupancy Evaluation (POE) applied in two office buildings which installations and technical support partially present automatic characteristics and are sited in the commercial corridor of Carlos Berrini avenue, Brooklin Novo district, São Paulo city.

It will introduce and discuss the format, the contents and the procedures to the application of questionnaires in order to measure the users' satisfaction of both buildings, presenting some comparative analyses and results regarding the evaluators and the users' point of views enlighting functional and behavioral aspects.

This discuss is a contribution to the development of procedures for the application of POE in Brazilian office buildings, which recently started and may have a significant advance, because of the fast increase of the tertiary sectors in the country's metropolitan regions. The research in sponsored by The State of São Paulo Foundation for Research Support (Fapesp).

A qualidade ambiental nos edifícios de escritórios, em função das distintas alternativas técnico-construtivas; das condições de conforto ambiental (térmica, ventilação, iluminação, acústica e ergonômica); das condições de segurança (contra crimes, acidentes, incêndio, outras); dos níveis de automação das instalações e serviços; das alternativas funcionais com base nas possiveis tipologias de pavimento e das relações entre aspectos físicos de desempenho, os níveis de satisfação dos usuários e a produtividade nestes locais de trabalho, há várias décadas vêm preocupando projetistas, pesquisadores, mantenedores, administradores, incorporadores e usuários (funcionários/consumidores) deste tipo de empreendimento. Pesquisas no âmbito da Avaliação Pós-Ocupação (APO) voltadas aos aspectos levantados inicialmente, contemplando diagnósticos e recomendações, podem ser apreciadas nos trabalhos do Center for Building Performance and Diagnostics, na Carnegie Mellon University, USA (Hartkopf et al., 1993); de Vischer (1989 a; b) e Marans (1991), dentre outros.

Estes trabalhos apresentam não só a aplicação da APO em diversos estudos de caso, mas também, uma ênfase metodológica, sobretudo no que diz respeito à elaboração de questionários para aferição da satisfação os usuários. Ainda quanto aos procedimentos

\section{Abstract}

Introdução:

Revisão bibliográfica 
metodológicos (questionários, entrevistas, diários, mapas comportamentais e outros), destaca-se o trabalho de Bechtel et al (1987) e uma vasta literatura complementar na área de marketing (Hayes, 1995). Também pesquisas aplicadas, mais específicas na área de conforto em ambientes de escritórios, vêm sendo elaboradas nos países desenvolvidos pelo menos desde a década de 70 (Lorens, 1995; Kroemer, 1995).

No Brasil, ainda são relativamente poucas as pesquisas de APO voltadas a edifícios de escritórios. Destacam-se, nos últimos três anos, dentre outras, aquela levada a cabo por Rheingantz (1995), que eferiu os níveis de satisfação dos usuários quanto ao conforto ambiental, no caso de edifício de escritórios de grande porte situado no Rio de Janeiro. Ainda, no contexto mais amplo da APO, abrangendo múltiplos aspectos, desde a inserção do edifício e seus usuários na vizinhança até variáveis funcionais, de conforto ambiental e comportamentais no pavimento tipo e recebendo apoio da Fundação de Amparo à Pesquisa do Estado de São Paulo (Fapesp), tem-se, desde 1994, pesquisa sendo desenvolvida junto ao NUTAU-USP, incluindo dois edifícios com determinados níveis de automação e dois edifícios convencionais situados na cidade de São Paulo (Ornstein, 1996; Romero et al., 1995). Deste trabalho, a etapa de aferição dos níveis de satisfação dos usuários, a partir da aplicação de questionários, já está concluída. Por outro lado, parcela significativa das discussões metodológicas mais recentes sobre APO, bem como a apresentação de estudos de caso distintos, está consubstanciada na obra de Ornstein, Bruna e Romero (1995).

Pretende-se demonstrar, neste artigo, o desenvolvimento e a aplicação de questionários no caso dos dois edifícios automatizados mencionados e alguns exemplos de resultados quanto à avaliação funcional e comportamental. Assim, para este efeito, doravante um dos edifícios será denominado "A" e o outro "B"

Os estudos de caso: Características básicas
Ambos os edifícios A e B, cuja aplicação de questionários se deu durante 1995, foram projetados, construídos e ocupados na década de 90 , abrigam empresas privadas com características de multinacionais e se localizam junto à Marginal do Pinheiros e ao corredor comercial supervalorizado da avenida Luis Carlos Berrini.

No setor da cidade em que se situam existem mais de 250 edifícios de escritórios (Folha de S. Paulo, 13 ago. 1995), sendo que o preço 
médio de venda por metro quadrado de escritórios está em torno de $\mathrm{R} \$ 1.319,00$, valor este, apenas inferior àquele detectado na avenida Paulista (R\$ 1.445,00 segundo a Folha de S. Paulo, 27 ago. 1995).

Ambos apresentam (em maior ou menor grau) diversos itens de instalações, serviços e sistemas de controle e de supervisão, gerenciados por computador (softwares), tais como elevadores, segurança contra incêndio, segurança contra furtos/controle de entrada e saída, iluminação artificial, condicionamento de ar, comunicações dentre outros aspectos. $O$ edifício $A$ tem uma área construída total cerca de $21 \%$ do edifício $B$, porém o primeiro apresenta um maior número de itens automatizados do que 0 segundo.

Tanto A quanto B seguem a concepção de landscape office que combina princípios de modulação e pré-cablagem de pisos, visando a maior flexibilidade possível na composição do mobiliário e rearranjos de layout em geral. $O$ edifício $A$, concentra serviços (elevadores, escadas, copa, sanitários, shafts) num ponto periférico e o B no centro da planta livre.

O edifício $A$ tem cerca de $12.000 \mathrm{~m}^{2}$ de área construída distribuídos por um subsolo, térreo e outros 5 pavimentos. O pavimento-tipo apresenta cerca de $1.200 \mathrm{~m}^{2}$ úteis, sendo que o arranjo espacial básico, à época do levantamento, pode ser visualizado na Foto 1 , a seguir:

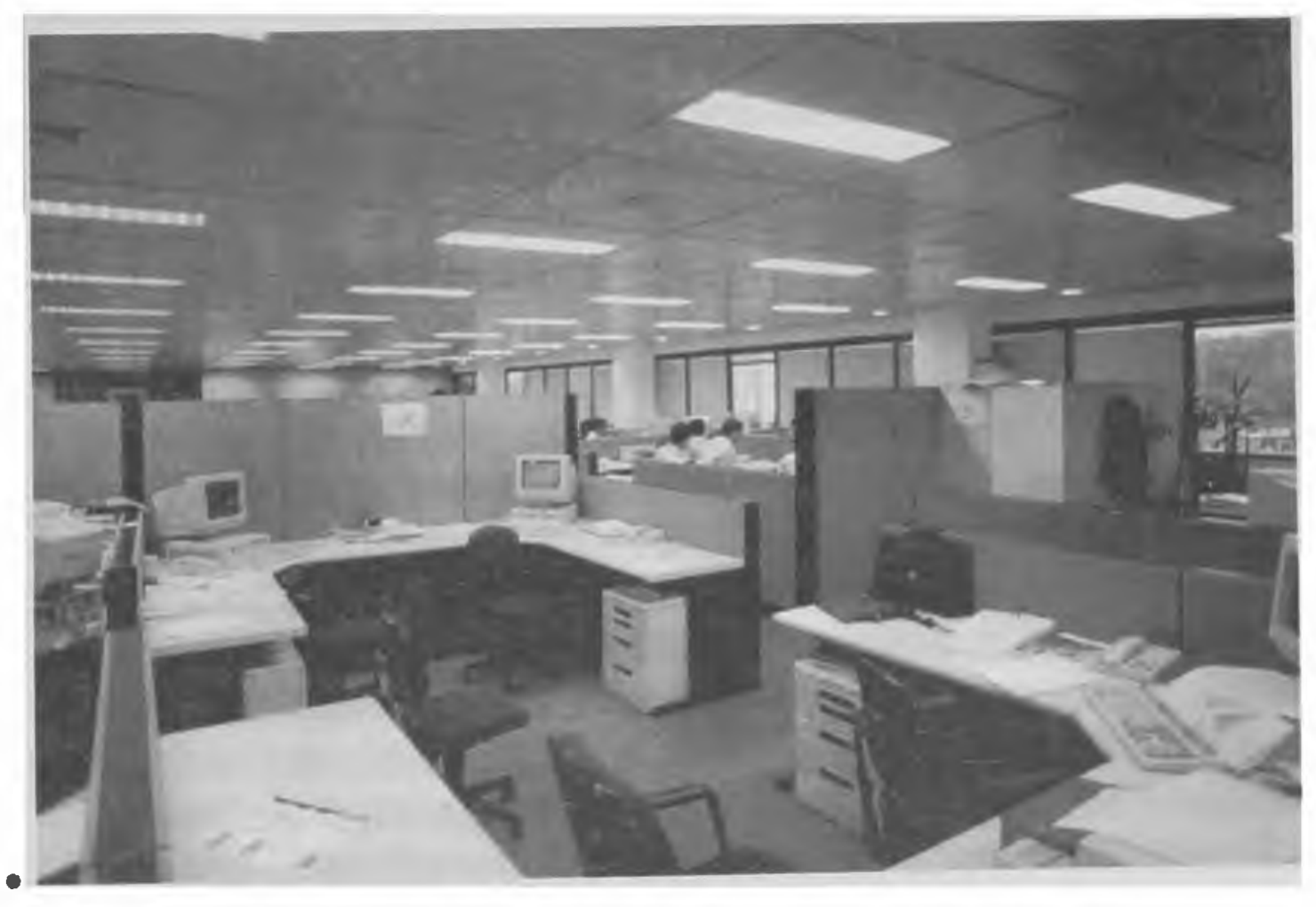

Foto 1 - Edifício A: Layout do pavimento-tipo, $3^{9}$ andar Fonte: Sheila Walbe Ornstein 
Foto 2 - Edifício B: Layout do pavimento-tipo, $11^{\circ}$ andar Fonte: Sheila Walbe Ornstein
O edifício B é constituído na realidade de uma torre, com subsolo, térreo e outros 20 pavimentos e dois anexos, totalizando $56.500 \mathrm{~m}^{2}$ de área construída, sendo que cerca de $71 \%$ refere-se à Torre de Escritórios (objeto central da pesquisa) e do Anexo I.

O pavimento-tipo apresenta aproximadamente $1.350 \mathrm{~m}^{2}$ de área útil, sendo que o arranjo espacial básico à época do levantamento pode ser visualizado na Foto 2, a seguir:

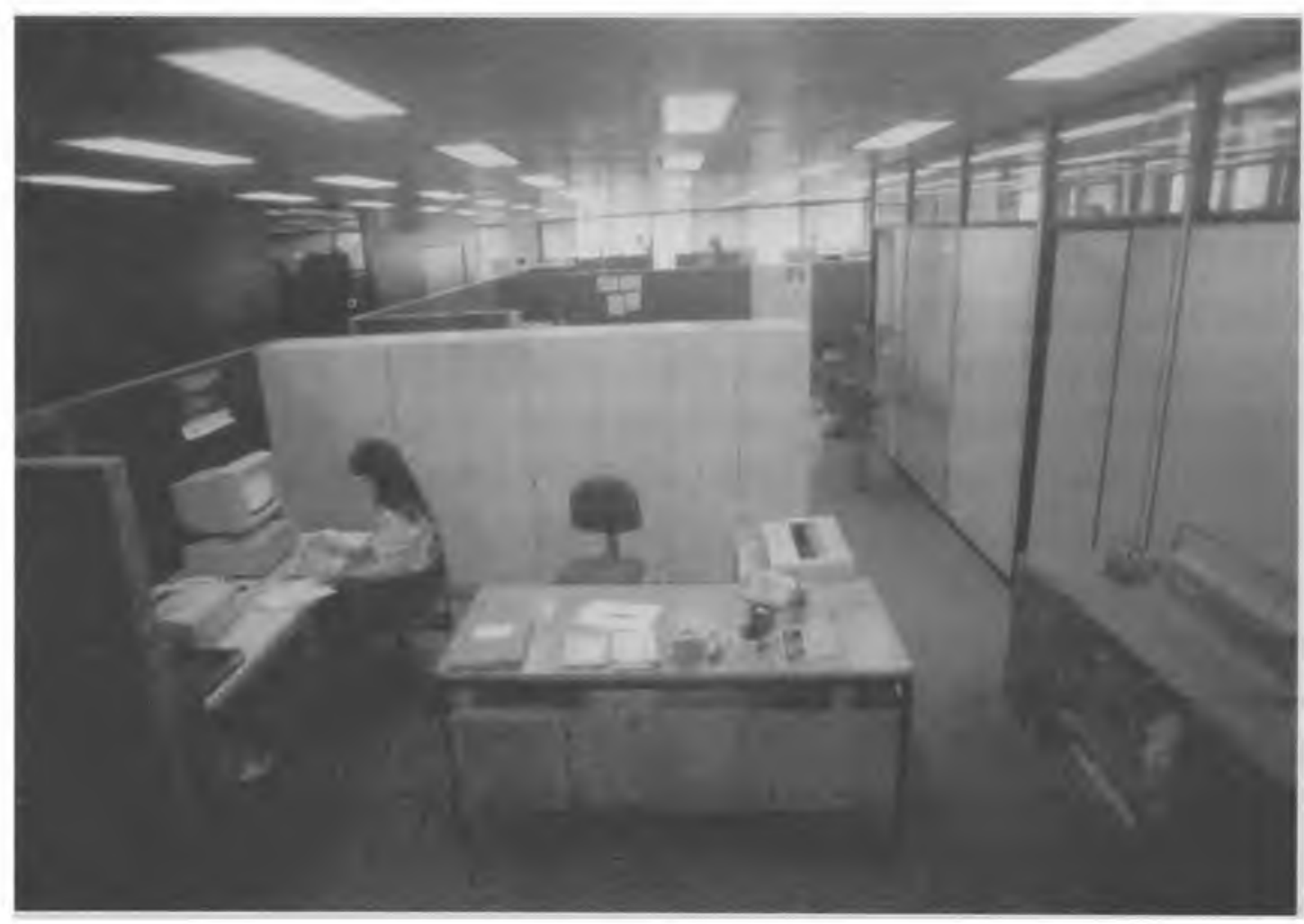

No caso do edifício A foram aplicados um total de 99 questionários perfazendo, à época do levantamento, cerca de $18,5 \%$ do universo de usuários. Quanto ao edifício B foi aplicado um total de 116 questionários, perfazendo $11 \%$ do universo de usuários.

O formato e o conteúdo do questionário proposto foi discutido com os alunos de graduação, de pós-graduação, demais docentes e pesquisadores e gerentes/administradores dos edifícios objetos de estudo, tendo sido, então, realizado o pré-teste. O questionário préteste foi aplicado no edifício A em cerca de $6 \%$ do tamanho estimado para a amostra e no edifício $B$ em cerca de $10 \%$. Assim é que o préteste aplicado em um número reduzido de respondentes foi confeccionado com linguagem para leigos, visou aferir a compreensão das perguntas, o tempo necessário para aplicação de cada questionário, se o conjunto de questões era suficiente em relação 
aos objetivos finais do trabalho; se estava eventualmente faltando algum item importante ou, mesmo, se havia sobreposição (desnecessária) de assuntos. Após a análise dos resultados (por alunos de graduação e de pós-graduação) foram feitos alguns ajustes e, então, aplicado o questionário definitivo.

Para aplicação do questionário definitivo também se estipulou algumas precondições, tais como, o respondente não poderia ter sido entrevistado anteriormente no pré-teste, o usuário deveria trabalhar regularmente nos edifícios, ou seja, de $2^{\mathrm{a}}$ a $6^{\mathrm{a}}$ feira $\mathrm{e}$ deveria estar trabalhando nestes locais há, no mínimo, 12 meses. A amostra de respondentes foi distribuída proporcionalmente pela quantidade total de usuários e por sexo, por pavimento. Além disto, na aplicação dos questionários, as equipes de alunos foram instruídas, no sentido de distribuir, o mais homogeneamente possivel (em relação à orientação solar do edifício), a aplicação dos questionários no espaço físico de cada pavimento, evitando, sempre que possível, concentrações de respondentes cujos locais de trabalho se situam próximos à envoltória. Sabe-se que estes critérios reduzem eventuais margens de erros ou distorções nas respostas, sobretudo naquelas referentes às características de conforto ambiental, de percepção e uso dos ambientes.

O questionário foi adotado como principal instrumento para aferição da satisfação dos usuários, a partir dos quais, os respondentes puderam expressar juízos de valor sobre diversos aspectos.

Assim é que o questionário definitivo incluiu cinco (05) blocos de questões ou de informações visando facilitar a tabulação e abrangendo: I - Características do Entrevistado (condições socioeconômicas; níveis de escolaridade; distância trabalhomoradia e outras); II Vizinhança (particularmente no que se refere à rede de serviços, comércio, transporte coletivo e outros elementos de infra-estrutura urbana disponiveis nas imediações); III - O Edifício como um todo (por exemplo, no que se refere à automação; segurança contra incêndio; segurança contra roubos; acesso ao deficiente físico; aparência; área de lazer e de convivência no edifício e desempenho do estacionamento); IV Pavimento, especialmente do pavimento-tipo, mas abrangendo também os pavimentos de cobertura e o térreo, incluindo diversas questões referentes à distribuição dos espaços e do mobiliário locais de trabalho; áreas comuns; de convivência/lazer; de reunião; 
localização de sanitários; circulação; almoxarifado - referentes ao conforto ambiental - térmico, lumínico, acústico, conservação de energia - referentes ao comportamento do usuário - visando aferir as formas de comunicação entre os usuários, as possibilidades de personalização e de privacidade dentre outros fatores; V Observações e comentários do entrevistado sendo que este último bloco, ou item, permitia comentários "livres" dos entrevistados.

Além disto, o questionário incluiu planta do pavimento-tipo em escala reduzida e orientação solar, visando localizar os respondentes em função das condições de conforto térmico e lumínico. Outros itens, também incluídos no questionário, auxiliaram na análise do conforto ambiental, aspecto este muito importante nos landscape offices com controle centralizado, por exemplo, da iluminação artificial e da temperatura. Dentre estes itens, destaca-se a marcação da situação do céu no horário da entrevista (claro, nublado, escuro); do tipo de vestimenta do entrevistado e outros.

O questionário foi organizado segundo técnicas quali-quantitativas, adotando-se perguntas abertas, semi-abertas e fechadas. Aquelas abertas e semi-abertas possibilitaram uma posterior classificação das respostas; aquelas fechadas exigiram respostas segundo escala de valores com 4 pontos discriminadas por adjetivos como insatisfeito (1); pouco satisfeito (2); satisfeito (3); muito satisfeito (4); ou péssimo (1); precário (2); bom (3); e ótimo (4). Ainda, no caso das questões fechadas, além dos 4 pontos da escala de valor, havia a possibilidade da resposta n.s.a. ou "não se aplica"

Avaliação funcional e comportamental: Exemplos de resultados
Ocorreu a tabulação quantitativa da grande maioria das respostas e da aplicação de análises estatísticas descritivas, tais como: média aritmética; a moda; o desvio-padrão e as freqüências absolutas e relativas. A tabulação, as análises estatísticas e os gráficos decorrentes foram feitos no software Windows, utilizandose 0 aplicativo Excel da Microsoft. A análise qualitativa das questões abertas também foram de grande valia nos diagnósticos e nas recomendações.

A seguir, a título de exemplificação, será apresentada a análise comparativa entre os edifícios estudos de caso dos resultados de 4 questões dirigidas à avaliação funcional (distribuição dos espaços e do mobiliário) e de 4 questões dirigidas à avaliação comportamental, lembrando-se que $N=99$ no caso do edifício 
A e $N=116$ no caso do edifício B. Ressalta-se ainda, que em ambos os edifícios mais de $70 \%$ dos respondentes apresentaram escolaridade "superior completo", sendo que respectivamente nos edifícios $A$ e $B, 89 \%$ e $65 \%$ dos respondentes encontram-se na faixa etária entre 20 e 40 anos (adultos), o que colabora na confiabilidade das respostas.

No caso do edifício A, a Figura 1 demonstra que quanto aos espaços para reuniões formais, existe tendência favorável ou positiva das respostas (em $54 \%$ dos casos), porém associadas a certa dispersão geral dos resultados ( $35 \%$ de insatisfatoriedade e $11 \%$ de "não se aplica"). Por outro lado, a análise qualitativa dos avaliadores demonstrou a necessidade de espaços adicionais para reuniões e adequação de mobiliário para este fim. No que se refere ao edifício B, observou-se que $90 \%$ dos entrevistados estão satisfeitos ou muito satisfeitos com este aspecto.

\section{Avaliação \\ Funcional}

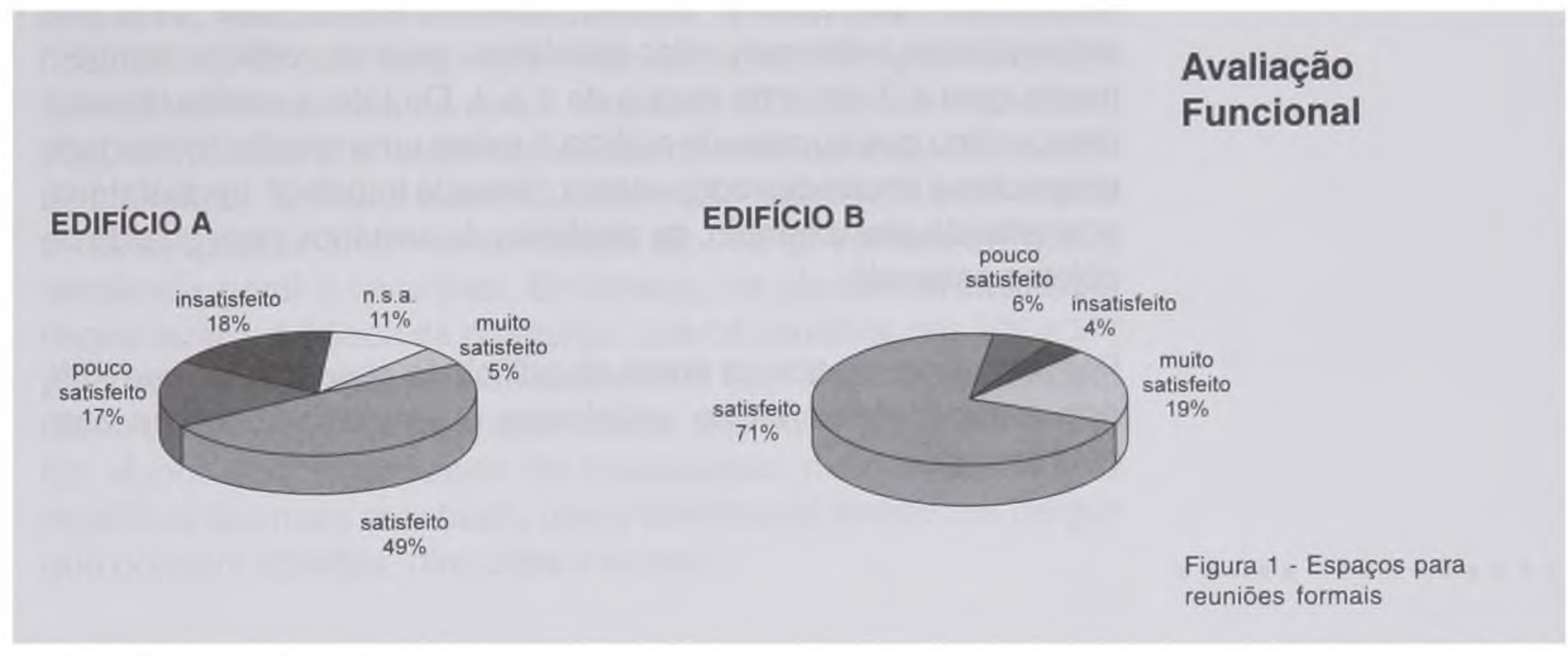

No caso do edifício A, a Figura 2 a seguir demonstra que $31 \%$ dos respondentes se manifestaram negativamente em relação aos espaços existentes para tal atividade, sendo que o "local do café" cumpre parcialmente este papel no pavimento-tipo. No caso do edifício B, também o "local do café" no pavimento-tipo cumpre este papel, a satisfação dos usuários foi significativamente mais elevada, pois $64 \%$ se manifestaram satisfeitos quanto a este aspecto. Nota-se, ainda, que as praças existentes nos pavimentos térreos, de ambos os edifícios, não foram consideradas no juízo de valores dos respondentes. 
Figura 2 - Espaço para reuniōes e contatos informais

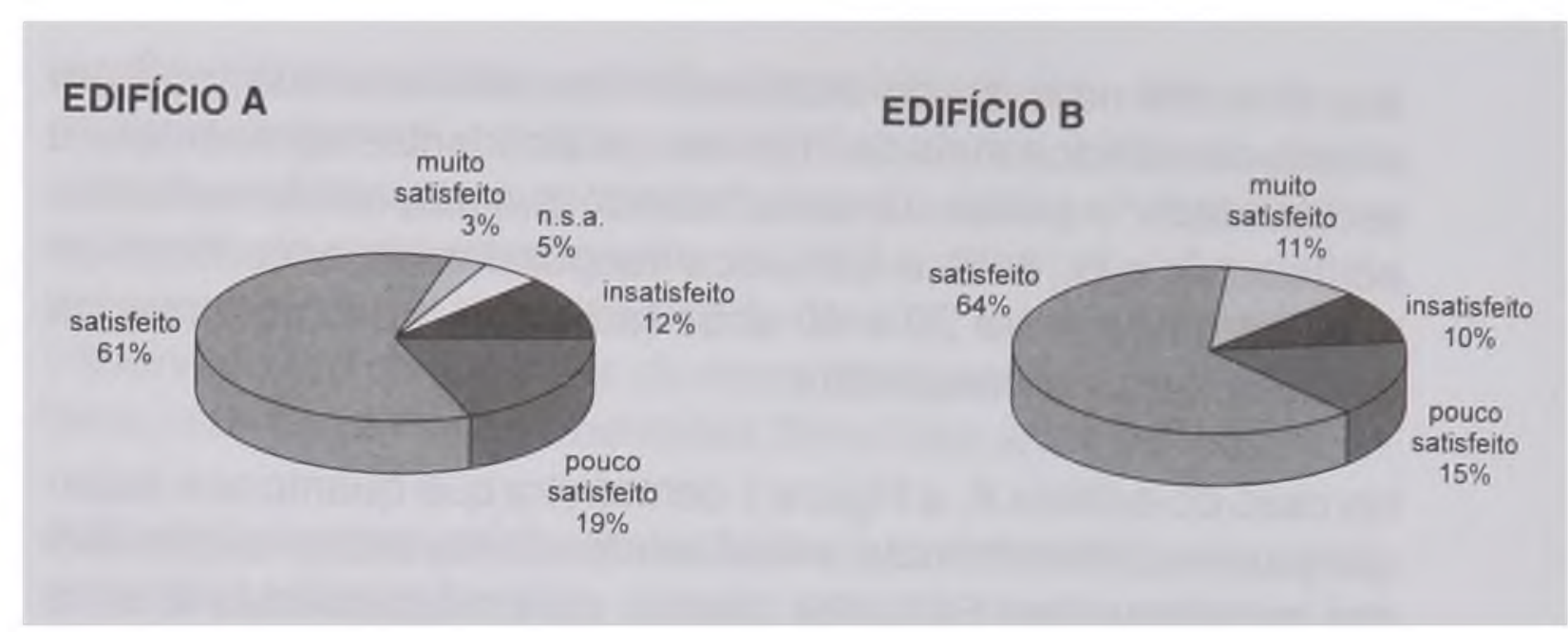

No caso do edifício A, conforme demonstra a Figura 3 abaixo, verificouse que $51 \%$ dos respondentes apresentaram insatisfação quanto a este aspecto, sendo a média atribuída, neste caso, igual a 2,23, dentro de uma escala de 1 a 4, considerando-se o indicador mínimo aceitável 2,50, e o desvio-padrão igual a 0,93 (Roméro et al., 1995). No caso do edifício $\mathrm{B}$, os entrevistados sugeriram desempenho favorável do pavimento-tipo, quanto a este aspecto, sendo que $59 \%$ dos entrevistados indicaram estar satisfeitos, pois se verificou também moda igual a 3 em uma escala de 1 a 4 . De fato, a análise técnica demonstrou que no caso do edifício A existe uma relação "densidade ocupacional (muito elevada) versus "área de trabalho" insatisfatória, acarretando, por exemplo, na ausência de armários para guarda de objetos pessoais.

Por outro lado, no que se refere ao edifício B, observou-se que $77 \%$ dos entrevistados estão satisfeitos ou muito satisfeitos com este aspecto.
Figura 3 - Espaço para armazenamento, arquivos, almoxarifados no pavimento

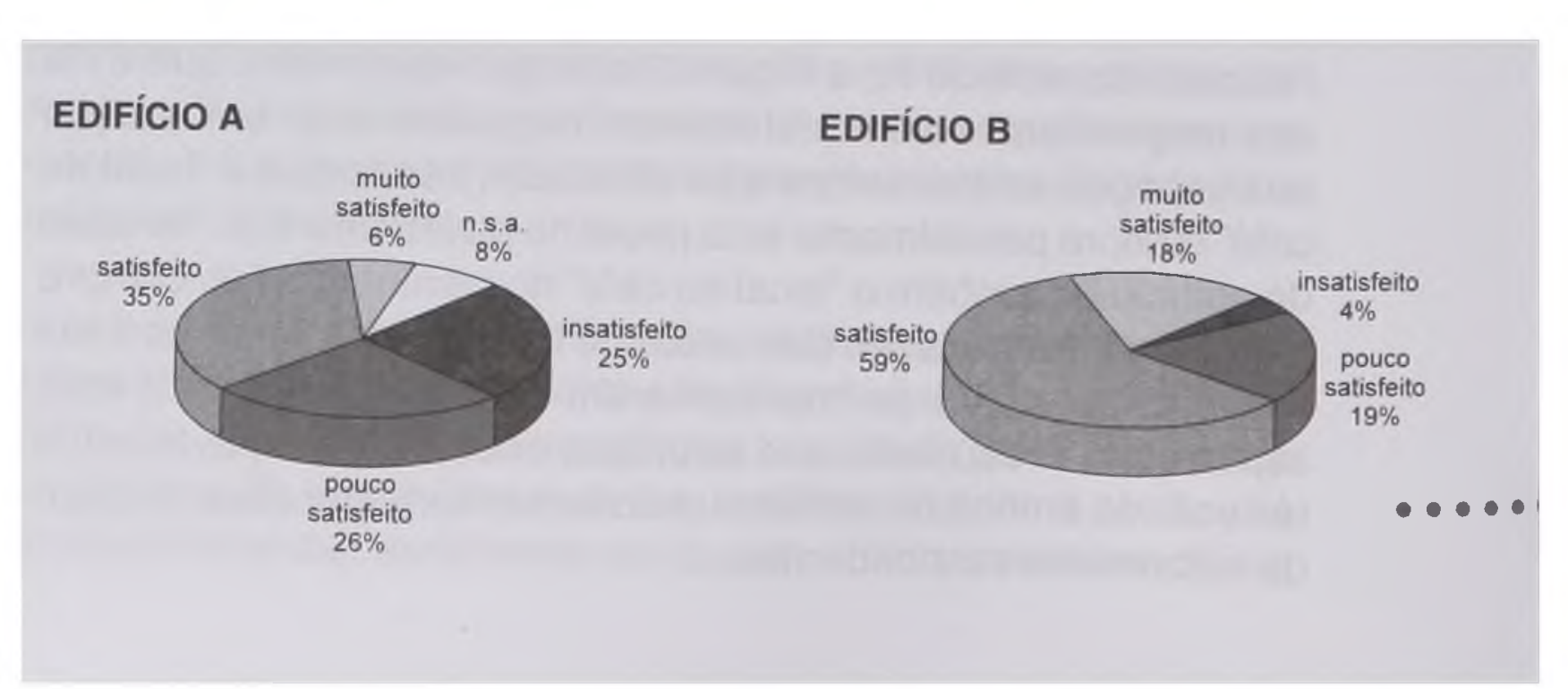




\section{EDIFÍCIO A}

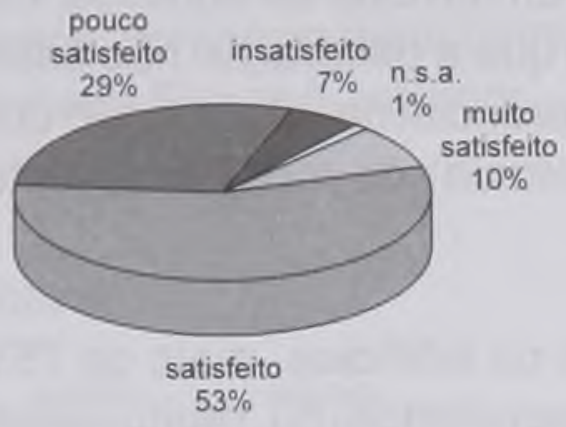

\section{EDIFÍCIO B}

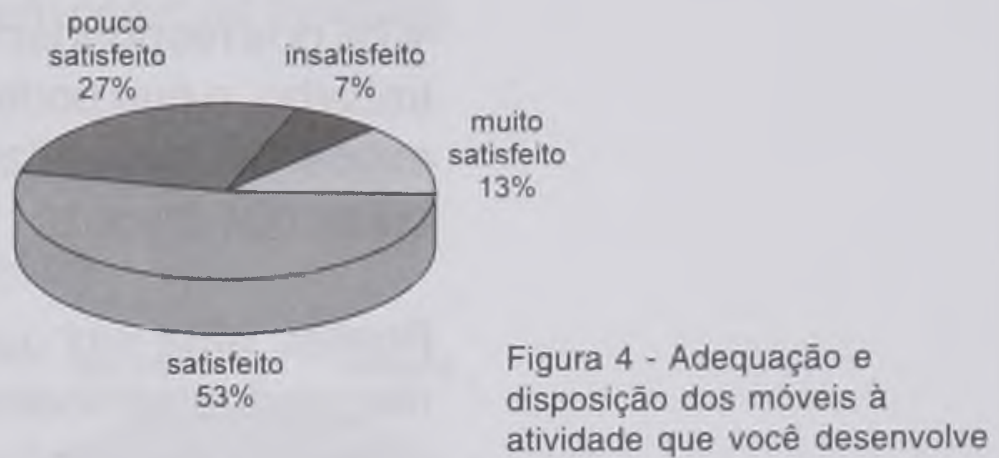

No caso do edifício A, $63 \%$ dos respondentes, conforme demonstra a Figura 4, se manifestaram satisfeitos ou muito satisfeitos em relação à adequação e à disposição dos móveis às atividades que desenvolvem.

Porém, cerca de $36 \%$ das respostas apresentaram tendência negativa, possivelmente associada à elevada densidade ocupacional do pavimento-tipo, impossibilidade de personalização do local de trabalho e as cores "neutras" do mobiliário, as quais, segundo parcela dos usuários, são pouco estimulantes. Já, no caso do edifício B, $53 \%$ dos entrevistados estão satisfeitos e em sendo a moda igual a 3 , em uma escala de 1 a 4 , verifica-se que a tendência geral é favorável. Entretanto, os alunos (avaliadores) constataram, à época da pesquisa, que os usuários dos $12^{\circ}$ e $17^{\circ}$ pavimentos não estão muito satisfeitos com este aspecto, bem como cerca de $50 \%$ dos entrevistados dos $16^{\circ}$ e $18^{\circ}$ pavimentos. Os alunos apontaram parte da insatisfação, nestes casos, pelo espírito crítico mais acentuado dos entrevistados devido aos cargos que ocupam (chefias, diretorias e outros).
EDIFÍCIO A

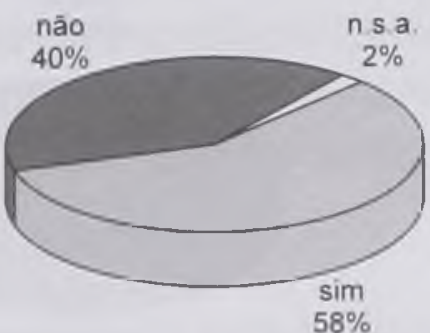

EDIFÍCIO B

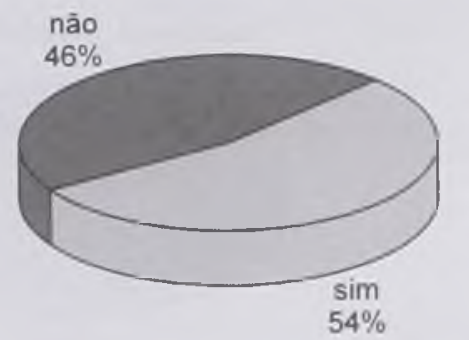

Avaliação comportamental
Figura 5 - A decoração do seu ambiente estimula o trabalho? 
Figura 6 - O nível de manutenção do edifício estimula o trabalho?
Conforme demonstra a Figura 5 anterior, ocorreu certo grau de dispersão das respostas. Porém em ambos os edifícios, mais de $40 \%$ dos respondentes indicaram que a decoração não estimula o trabalho, o que poderia ser um referencial da insatisfação quanto à excessiva padronização (e monotonia) do mobiliário, texturas e cores dos layouts.

Porém, uma vez que, em ambos os edifícios, mais de $75 \%$ dos respondentes indicaram estar satisfeitos ou muito satisfeitos quanto à disposição de objetos pessoais no seu local de trabalho (personalização ou individualização), conforme demonstra a Figura 7 , associada à questão destacada na Figura 5, acreditase que as respostas de tendência positiva ou "sim" possam ser confiáveis.

\section{EDIFícIO A}

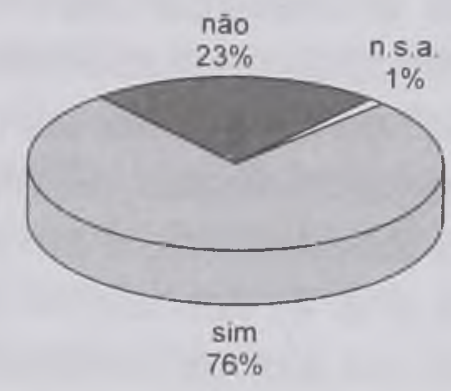

\section{EDIFÍCIO B}

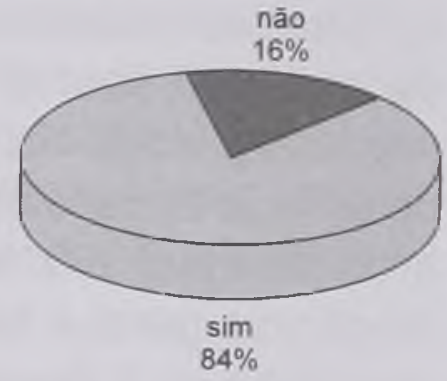

Figura 7 - Disposição de objetos pessoais no seu local de trabalho

Tanto no caso do edifício A, quanto no caso do edifício $B$, as respostas à questão referente à Figura 6 demonstram que os respondentes consideram a manutenção e a conservação dos edifícios, muito satisfatórios, podendo estes fatores serem considerados como estímulos à produtividade.

\section{EDIFÍCIO A}

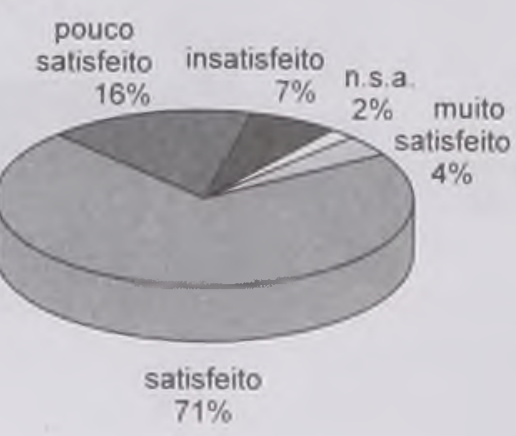

EDIFÍ́CIO B

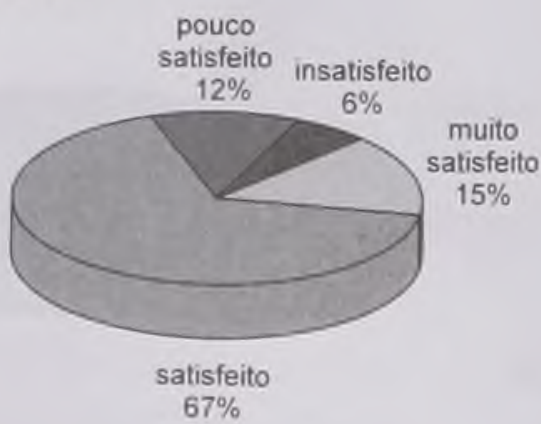


No caso da possibilidade de dispor objetos pessoais no local de trabalho, os respondentes demonstraram estar consideravelmente satisfeitos, conforme demonstra a Figura 7, bem como as análises referentes à Figura 5, anterior.

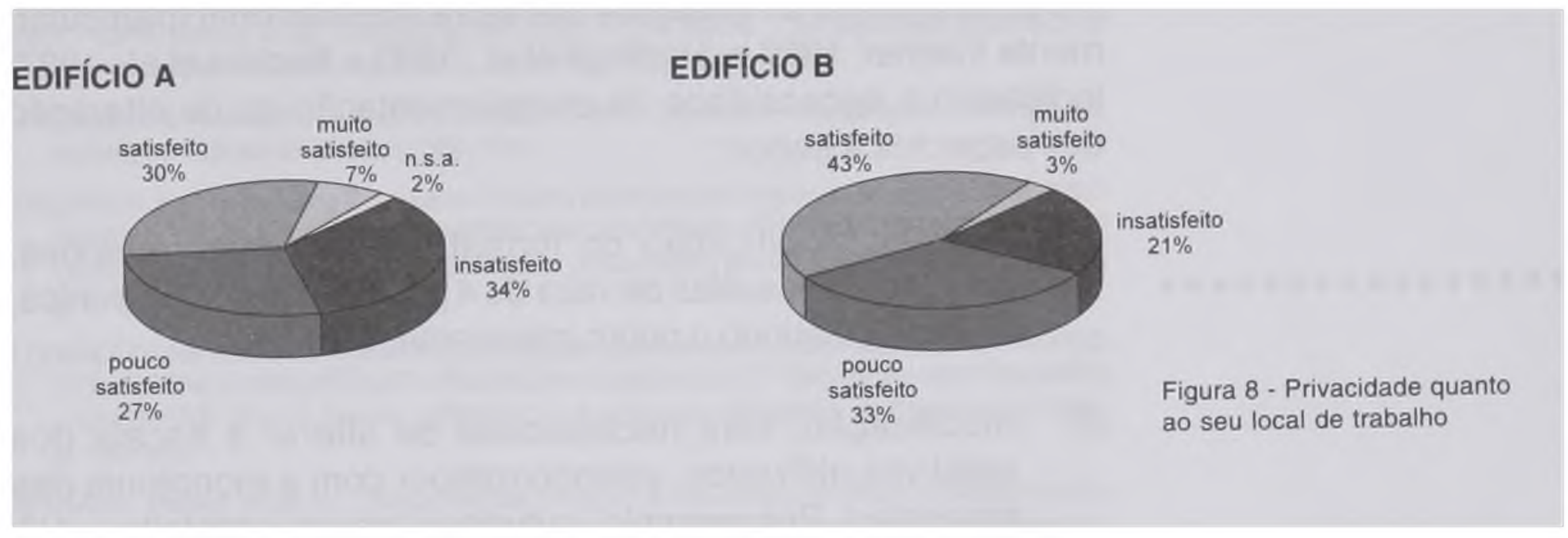

Conforme demonstra a Figura 8, anterior, os respondentes em ambos os edifícios demonstraram significativo grau de insatisfação quanto ao aspecto "privacidade no local de trabalho", sendo que $61 \%$ dos entrevistados do edifício $A$ se manifestaram desfavoravelmente $e$ no caso do edifício $B$, este percentual atinge $54 \%$.

De fato, o landscape office impõe falta de privacidade acústica, física (divisórias a $1 / 2$ altura) e visual do pavimento-tipo, com propagação intensa de sons simultâneos: vozes, pessoas conversando; digitação, telefonemas, etc., apesar do tratamento acústico relativo de pisos e divisórias.

Ficou demonstrado, a partir da aplicação de questionários nos edifícios A e B, que este instrumento associado a escala de valores, é eficiente nas APOs em edifícios de escritórios, tendo em vista a aferição da satisfação dos usuários, sobretudo quando o respondente é adulto com elevado nivel de escolaridade. Especialmente nas análises funcionais (arranjo espacial) e das condições de conforto e comportamentais, a aferição da satisfação pode contribuir com as atividades de melhoria da qualidade dos espaços de trabalho.

A experiência nos edifícios A e B, automatizados, sugeriu, todavia, que deveria ocorrer alguns ajustes no formato e no conteúdo do

Discussão sobre os questionários e conclusões 
questionário proposto, sem prejuízo da possibilidade de comparação dos resultados, quando da tabulação e análise qualiquantitativas com os edifícios $C$ e $D$, convencionais, também inseridos como estudos de caso na mesma pesquisa. Assim é que a análise de utilização de questionários, no caso dos edifícios $A$ e $B$, bem como a revisão da literatura internacional (particularmente Vischer, 1989 a; Hartkopf et al., 1993 e Bechtel et al., 1987) indicaram a necessidade de complementação ou de alteração dos aspectos a seguir:

(I) inclusão/modificação do formato de algumas questões, alterando-se escalas de valor de 4 pontos, para 3 ou 5 pontos, ou seja, inserindo o ponto intermediário ou neutro;

(II) modificação, sem necessidade de alterar a escala dos adjetivos utilizados, visando romper com a monotonia das respostas. Por exemplo, substituir "pouco satisfeito $(=1)$ "; "insatisfeito (=2)"; "satisfeito (=3)"; "muito satisfeito $(=4)$ " por "muito inadequado (=1)"; "inadequado (=2)"; "adequado $(=3)$ ". "muito adequado $(=4)$ ";

(III) inserção de questões específicas associadas ao posto de trabalho (ergonomia);

(IV) análise qualitativa acurada das respostas abertas, uma vez que estas colaboram na compreensão das respostas quantitativas de tendência negativa; $e$,

(V) utilização visual quando das análises comparativas entre respostas de um mesmo edifício e entre mesmas respostas de edifícios distintos; de Diagramas de Paretto com base médias, modas e desvios-padrão oriundos das escalas numéricas de valores.

Por outro lado, verificou-se que, no caso brasileiro, mesmo considerando o elevado padrão técnico-construtivo geral dos edifícios $A$ e $B$, as recomendações decorrentes da APO devem ter em conta não só os níveis de satisfação dos usuários, mas também a análise técnica do edifício como um todo e de cada ambiente, feita pelos próprios avaliadores (Ornstein, Bruna, Romero, 1995). 
AMARAL, Rodrigo. Globalizaçāo traz prédios inteligentes a Sāo Paulo. In: Folha de S. Paulo. São Paulo, 13 ago. 1995.

Remoção de favela supervaloriza. Berrini. Folha de S. Paulo. São Paulo, 27 de ago. 1995 (p. 9-1 e 9-3).

BECHTEL, Robert B. et al. Methods in environmental and behavioral research. Nova York: Van Nostrand Reinhold, 1987.

HARTKOPF, Volker et al. Designing the office of the future: The japanese approach to Tomorrow's Workplace. Nova York: John Wiley \& Sons, Inc., 1993.

HAYES, Bob E. Como medir la satisfacción del cliente: Desarollo y utilización de cuestionários. Barcelona: Ediciones Gestión 2000, 1995.

KROEMER, Karl H. Averting Cumulative Trauma Disorders in Shop and Office. In: IEA WORLD CONFERENCE 1995; 3 RD LATIN AMERICAN CONGRESS; 7 TH BRAZILIAN ERGONOMICS CONGRESS. Rio de Janeiro: ABERGO - Associação Brasileira de Ergonomia, 1995. p. 171-173.

LORENZ, Dieter. Flexible Office Buildings for Organizational and Human Needs. In: IEA WORLD CONFERENCE 1995; 3 RD LATIN AMERICAN CONGRESS; 7 TH BRAZILIAN ERGONOMICS CONGRESS. Rio de Janeiro: ABERGO - Associação Brasileira de Ergonomia, 1995. p. 159-162.

MARANS, Robert W. et al. Environmental change: A case study of office relocation at the University of Michigan. Ann Arbor, Michigan: College of Architecture and Urban Planning, The University of Michigan, 1991.

ORNSTEIN, Sheila Walbe. Inovação em edifícios de escritórios. Diário do Grande ABC. Santo André, 23 jun. 1996. p. I-1.

ORNSTEIN, Sheila; BRUNA, Gilda; ROMÉRO, Marcelo. Ambiente construído \& comportamento: $A$ avaliação pós-ocupação e a qualidade ambiental. São Paulo: Studio Nobel, Faculdade de Arquitetura e Urbanismo da Universidade de São Paulo, Fundação para a Pesquisa Ambiental, 1995.

RHEINGANTZ, Paulo Ałonso. Centro Empresarial Internacional Rio: Análise Pós-Ocupação por observação participante das condições internas de conforto. Rio de Janeiro, 1995. Dissertação (Mestrado) - Faculdade de Arquitetura e Urbanismo, Universidade Federal do Rio de Janeiro.

ROMÉRO, Marcelo et al. A contribuição da Avaliação Pós-Ocupação (APO) para a qualidade do projeto: Estudo de caso de um edifício de escritórios. In: ENTAC 95 - QUALIDADE E TECNOLOGIA NA HABITAÇÃO. Anais. Rio de Janeiro, ANTAC - Associação Nacional de Tecnologia do Ambiente Construído, 1995. pp. 269-274.

VISCHER, Jacqueline C. Environmental quality in offices. Nova York: Van Nostrand Reinhold, 1989. (a).

Building - In use assessment: Analysis of office buildings. In: Building Evaluation. Nova York: Plenum Press, 1989. p. 317-325. (b).

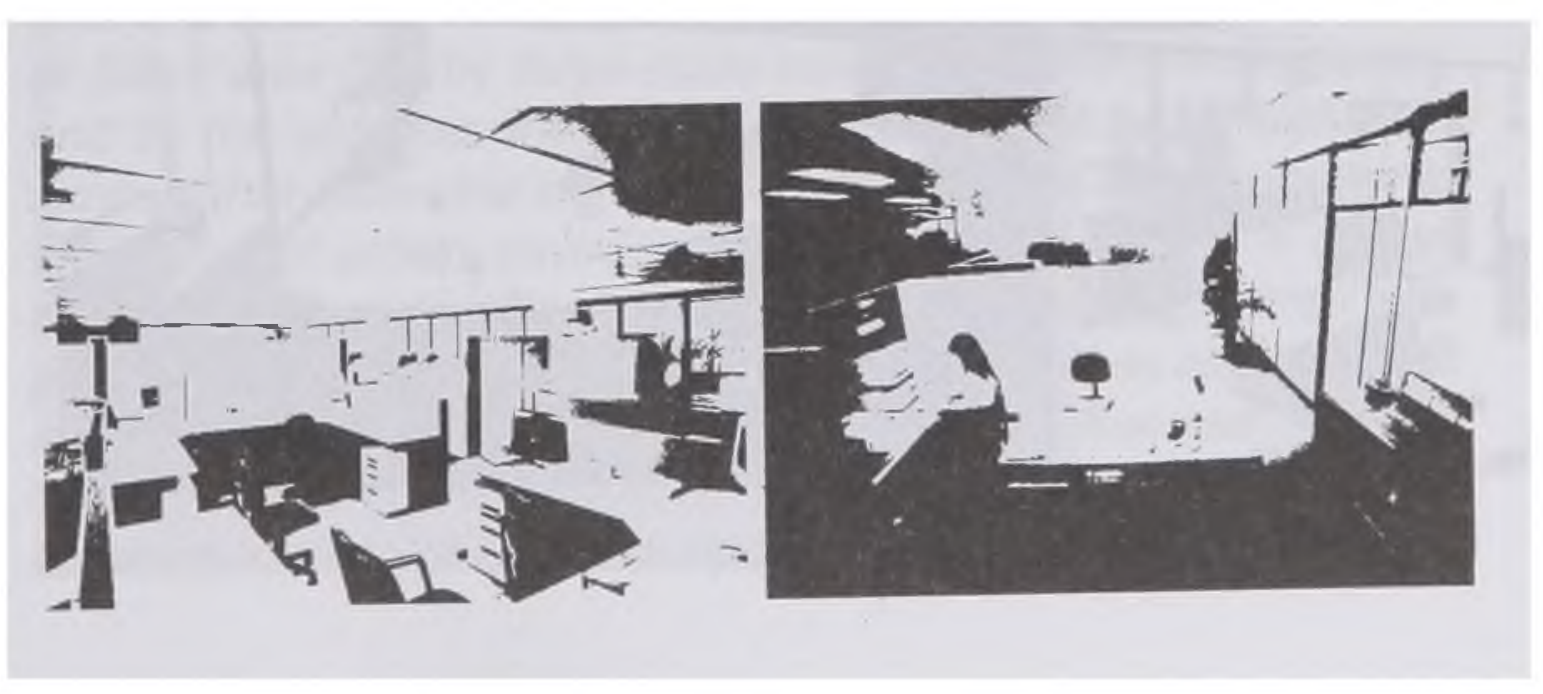




\section{* NOTAS}

(a) a aplicação de questionários bem como a tabulação de dados, contou em 1995, com a colaboração dos graduandos da FAUUSP junto à disciplina AUT-537 - Avaliação PósOcupação como Metodologia de Projeto, dos pós-graduandos junto à AUT-805 - Avaliação Pós-Ocupação dos Edifícios e da doutoranda na FAUUSP arquiteta Rosária Ono;

(b) este trabalho foi apresentado no NUTAU'96 - Seminário Internacional de Tecnologia da Arquitetura e Urbanismo, ocorrido na FAUUSP no período de 31 de outubro a 02 de novembro de 1996.
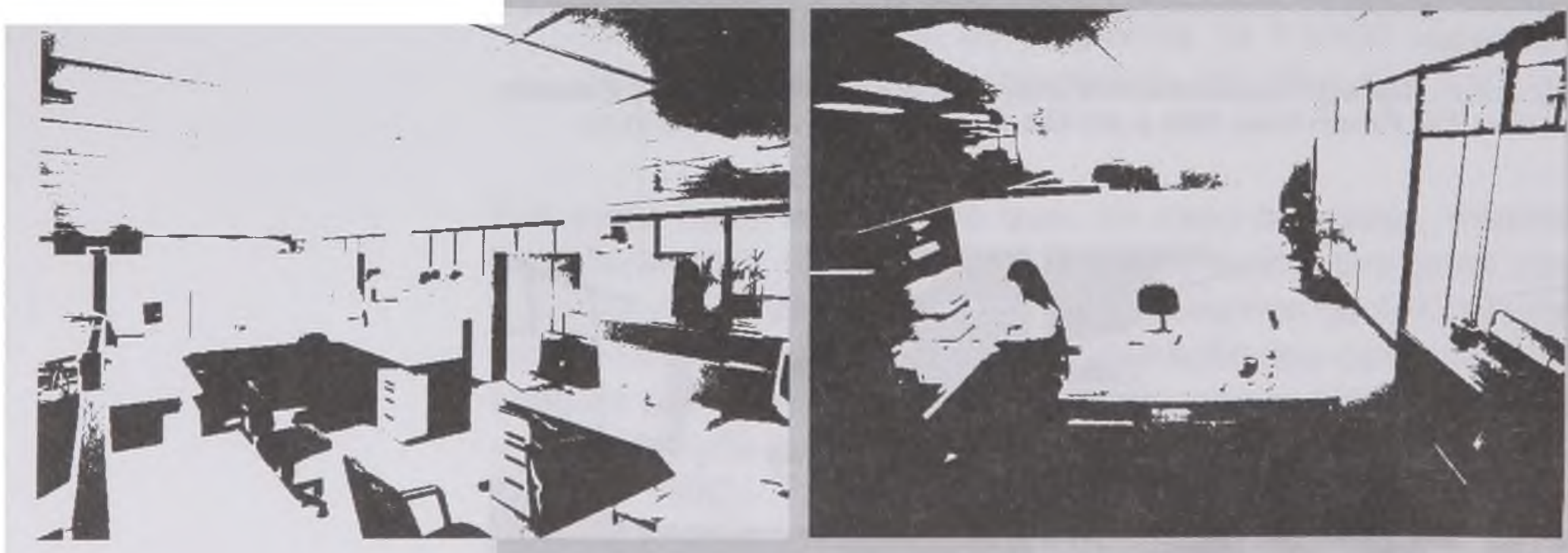